PII S0016-7037(96)00387-0

\title{
Experimental constraints on the origin of lunar high-Ti ultramafic glasses
}

\author{
T. P. Wagner and T. L. Grove \\ Department of Earth, Atmospheric, and Planetary Science, Massachusetts Institute of Technology, Cambridge, Massachusetts 02139, USA
}

(Received February 13, 1996; accepted in revised form November 11, 1996)

\begin{abstract}
Phase equilibria and dissolution rate experiments are used to develop a petrogenetic model for the high-Ti lunar ultramafic glasses. Near-liquidus phase relations of the Apollo 14 black glass, the most Ti-rich lunar ultramafic glass, are determined to $2.2-\mathrm{GPa}$. The liquidus is saturated with $\mathrm{Cr}$-spinel at 1 -atm, olivine between $\sim 0.5$ - and 1.5-GPa, and low-Ca pyroxene $+\mathrm{Cr}$-spinel above 1.5-GPa. Ilmenite does not crystallize near the liquidus and implies that high-Ti ultramafic glasses are not produced by melting of an ilmenite-saturated source. We infer that high-Ti ultramafic magmas are derived from lowTi ultramafic parent magmas by assimilation of ilmenite \pm clinopyroxene \pm urKREEP \pm pigeonite in the shallow lunar interior. Heat is provided by adiabatic ascent of the low-Ti ultramafic primary magmas from the deeper lunar interior and crystallization of olivine during assimilation. The assimilation reaction is modeled by mass balance and requires that ilmenite and high- $\mathrm{Ca}$ pyroxene are assimilated in a $\sim 3: 1$ ratio, a much higher ratio than the proportion in which these minerals are thought to exist in the lunar interior. In an effort to understand the kinetic controls on this reaction, the dissolution of ilmenite is examined experimentally in both low- and high-Ti lunar magmas. We find that ilmenite dissolves incongruently to $\mathrm{Cr}$-spinel and a high-Ti melt. The dissolution reaction proceeds by a diffusion-controlled mechanism. An assimilation model for the origin of high-Ti melts is developed that leaves the magma ocean cumulates in their initial stratigraphic positions and obviates source hybridization models that require lunar overturn. Copyright $\mathbb{C} 1997$ Elsevier Science Ltd
\end{abstract}

\section{INTRODUCTION}

Lunar volcanic rocks vary widely in $\mathrm{Ti}$ content, from 0.26 to $16.4 \mathrm{wt} \% \mathrm{TiO}_{2}$ (Fig. 1). Many models have been proposed to explain this broad chemical variation and each has distinctly different implications for the evolution of the lunar interior. The moon's interior is considered to consist of mineralogically diverse cumulate zones produced by an early $(\sim 4.5 \mathrm{Ga}$.) magma ocean differentiation event, as proposed by Smith et al. (1970) and Wood et al. (1970) (reviewed in Warren, 1985). Models of magma ocean crystallization (e.g., Taylor and Jakes, 1974; Walker et al., 1975a; Longhi, 1977; Snyder et al., 1992) suggest that the deepest cumulates are primarily ol \pm low-Ca pyroxene, which crystallized near or sank to the base of the magma ocean, while the uppermost cumulates are primarily plagioclase, which floated upward in the ocean and formed the anorthositic crust. Highly fractionated liquid was trapped between the deep mafic cumulates and anorthositic crust or dispersed in the interstices of the cumulates at approximately $100-\mathrm{km}$ depth. This liquid was enriched in $\mathrm{Ti}, \mathrm{Fe}$, and other incompatible elements. It crystallized ilmenite and a range of silicates and also contains the urKREEP. the final dregs of liquid from magma ocean crystallization (Warren and Wasson, 1979).

Low-Ti lunar magmas are thought to have formed primarily by a partial melting process that left an ol \pm low-Ca pyroxene bearing residue (e.g., Longhi, 1992). The high-Ti contents and correspondingly higher trace element abundances of high- $\mathrm{Ti}$ lunar magmas are attributed to the shallower, ilmenite-bearing layer, but its role in high-Ti lunar volcanism remains unclear. In early models, the ilmenite bearing cumulates melted to produce high-Ti magmas (e.g.,
Taylor and Jakes, 1974; Walker et al., 1975b). These models proved inconsistent with experimental studies of the ultramafic glasses that showed both low- and high-Ti ultramafic glass compositions were saturated with olivine and low-Ca pyroxene at similar depths $(\sim 300-\mathrm{km})$. Hubbard and Minear (1975) proposed that high-Ti magmas were derived from low-Ti primary magmas that assimilated shallow ilmenite-bearing cumulates en route to the surface. This model was rejected by Ringwood and Kesson (1976) based on suppositions of the proportions of assimilants and the thermal energy budget of the reaction. Lacking an adequate model in a static moon, Ringwood and Kesson (1976) proposed a dynamic overturn model, where the ilmenite-bearing layer sank into the lunar interior. This sinking event mixed the high- and low-Ti parts of the cumulate pile and formed hybridized source zones, the melting of which could produce magmas with a wide range of Ti contents. Subsequent physical models of the moon predicted overturn of the magma ocean cumulate pile (e.g., Herbert, 1980). A number of variations of the overturn and source mixing model have been proposed by Hess (1991, 1993) and Hess and Parmentier (1995) that also produce high-Ti magmas and a lunar core.

Herein, we critically reevaluate the assimilation model for the formation of lunar high-Ti magmas by modeling the major element chemical variation observed in the lunar ultramafic glasses. These ultramafic glasses are most similar to high-Mg mare basalts (e.g., Ridley et al., 1973), but have consistently higher $\mathrm{Mg}, \mathrm{Ni}$ and molar $\mathrm{Mg} /(\mathrm{Mg}+\mathrm{Fe})$ and hence are the best candidates for primary magmas found on the moon. Extensive study of the ultramafic glasses by Delano (1986) has lead to the identification of twenty-five prim- 


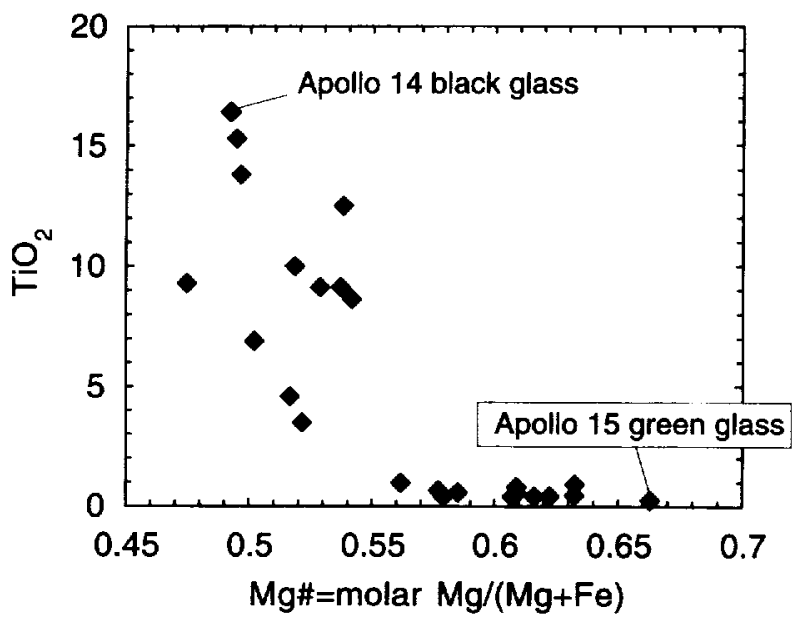

Fig. 1. Plot of $\mathrm{TiO}_{2}$ in wt\% against $\mathrm{Mg} \#$ (molar $\mathrm{Mg} / \mathrm{Mg}+\mathrm{Fe}$ ) of most primitive lunar glasses of Delano (1986).

itive endmembers that show fiftyfold variation in $\mathrm{TiO}_{2}$-content (Fig. 1), a broader range than exhibited by the mare basalts.

\section{EXPERIMENTAL AND ANALYTICAL METHODS}

\subsection{Phase Equilibria Experiments}

\section{I.I. Starting materials}

The near-liquidus phase relations of a synthetic analog of Apollo 14 (AP 14) black glass (Delano, 1986) were determined in melting experiments from $1-\mathrm{atm}$ to $2.2-\mathrm{GPa}$. This composition was chosen because it has the highest $\mathrm{TiO}_{z}$-content of the high-Ti ultramafic glasses. The synthetic analog of this glass composition (Table 1) was prepared from high-purity oxides and silicates and ground in an agate mortar under ethyl alcohol for $6 \mathrm{~h}$ to ensure homogeneity.

\subsubsection{1-atm Experiments}

Each 1-atm experiment was conducted using approximately 50mg of AP 14 black glass powdered mix, pressed into a pellet using Elvanol as a binding agent. The pellet was sintered to a $0.8-\mathrm{mm}$ diameter, Fe-Pt loop fabricated to minimize Fe-exchange with the silicate melt. The loop was hung in the hotspot of a Deltech DT3IVT vertical quenching furnace. All experiments were performed at an oxygen fugacity corresponding to $\mathrm{Fe}-\mathrm{FeO}$ using constant mixing proportions of $\mathrm{H}_{2}$ and $\mathrm{CO}_{2}$ gases with flow rates of approximately $0.1-\mathrm{mL} / \mathrm{s}$. Oxygen fugacity was monitored using a $\mathrm{ZrO}_{1}-\mathrm{CaO}_{\text {elec- }}$ trolyte cell calibrated at the $\mathrm{Fe}-\mathrm{FeO}$ buffer. Temperature was moni- tored with Pt-Pty $\mathrm{Rh}_{10}$ thermocouples calibrated against the melting points of $\mathrm{NaCl}, \mathrm{Au}$, and Pd on the IPTS 1968 temperature scale. Experiments were drop-quenched into water. Temperature was varied to constrain the liquidus temperature and first crystalline phase appearance.

\subsubsection{High pressure experiments}

Starting material for the high pressure experiments was prepared by pressing $500-\mathrm{mg}$ of powdered mix into a pellet using Elvanol as a binding agent. The pellet was hung on 0.004 " Pt wire and conditioned at an oxygen fugacity corresponding to the $\mathrm{Fe}-\mathrm{FeO}$ buffer at $1075^{\circ} \mathrm{C}$ for $24 \mathrm{~h}$ using the same furnace and techniques employed for the 1 -atm experiments. $10 \mathrm{mg}$ of conditioned starting material was placed in a graphite crucible and welded shut in a Pt outer capsule. These capsules were placed in an alumina sleeve and positioned in the hotspot of a graphite heater with MgO spacers. Experiments were performed in a 0.5 " piston-cylinder apparatus, similar to the design of Boyd and England (1960), using $\mathrm{BaCO}_{3}$ as the pressure medium. Pressure was calibrated against the transition of anorthite-gehlenite-corundum to Ca-Tschermak's pyroxene as determined by Hays (1965). Temperature was monitored with $W_{47} R_{3}$ $W_{75} \operatorname{Re}_{25}$ thermocouples with no correction applied for pressure. The thermal gradient near the hotspot was measured at $20^{\circ} \mathrm{C} / 0.1^{\prime \prime}$. Sample thickness is $<0.05^{\prime \prime}$, resulting in a thermal gradient of $<10^{\circ} \mathrm{C}$. Runs were pressurized cold to $1.0-\mathrm{GPa}$ and then heated to $865^{\circ} \mathrm{C}$ at $100^{\circ} \mathrm{C} / \mathrm{min}$ where they were held for $6 \mathrm{~min}$. They were then pumped to desired run pressure and heated to final run temperature at $50^{\circ} \mathrm{C} /$ min. Experiments were quenched by shutting off the power. Experiments above 1.5-GPa were decompressed to 1.0-GPa immediately prior to quenching to prevent the formation of quench crystals in the liquid regions of the charge (Putirka et al., 1996).

Experiments were performed over a pressure range of 1-2.2-GPa and a temperature range that spanned the liquidus and subliquidus phase boundaries ( Table 2 ). All observed primary phases were analyzed (Table 3). A materials balance calculation was used to estimate the phase proportions (Table 2) and determine whether the silicate charge had changed composition during the experiment. The silicate charge can lose $F e$ to the Pt capsules if fractures form in the graphite crucibles and allow the liquid phase to contact the Pt outer capsule. Experiments where the materials balance calculation showed FeO loss of $>1 \%$ relative were discarded.

\subsection{Imenite Dissolution Experiments}

\subsubsection{Starting materials}

The dissolution rate of ilmenite was determined in both low- and high-Ti lunar magmas (Table I). The ilmenite portion of the charge was cut from a homogeneous ilmenite megacryst from the Frank Smith kimberlite mine. South Africa. The megacryst is polycrystalline but completely unaltered, which is rare for large ilmenite samples. Trace amounts of sulfide are present along some grain boundaries. Synthetic analogs of the lunar magma compositions (Table 1) were prepared and conditioned at an oxygen fugacity corresponding

Table 1. Starting materials used in experiments.

\begin{tabular}{|c|c|c|c|c|c|c|c|c|c|c|c|c|}
\hline Sample & $\mathrm{MgO}$ & $\mathrm{Al}_{2} \mathrm{O}_{3}$ & $\mathrm{SiO}_{2}$ & $\mathrm{CaO}$ & $\mathrm{TiO}_{2}$ & $\mathrm{Cr}_{2} \mathrm{O}_{3}$ & $\mathrm{MnO}$ & $\mathrm{FeO}$ & $\mathrm{Na}_{2} \mathrm{O}$ & $\mathrm{K}_{2} \mathrm{O}$ & $\mathrm{Ni}$ & $\overline{\mathrm{P}_{2} \mathrm{O}_{5}}$ \\
\hline & & Phase & equil & ibria st & tudy & & & & & & & \\
\hline Apollo 14 black glass & 13.3 & 4.6 & 34.0 & 6.9 & 16.4 & 0.92 & 0.31 & 24.5 & 0.23 & 0.16 & - & - \\
\hline \multicolumn{13}{|c|}{ Ilmenite dissolution rate study } \\
\hline Ilmenite, $F$ & 11.4 & 0.64 & 0.13 & 0.07 & 51.8 & 1.70 & 0.17 & 33.2 & - & - & 0.22 & \\
\hline Apollo 15 green glass, group C & 18.2 & 7.74 & 48 & 8.57 & 0.26 & 0.57 & 0.19 & 16.5 & - & - & - & - \\
\hline Apollo 11 high-K basalt, 10072 & 7.64 & 7.89 & 41.2 & 10.5 & 12 & 0.28 & 0.24 & 19.4 & 0.34 & 0.27 & - & 0.19 \\
\hline Luna- 24 ferrobasalt & 6.31 & 12.6 & 47.1 & 12.8 & 0.88 & 0.23 & 0.25 & 20.2 & 0.2 & 0.02 & - & \\
\hline
\end{tabular}

Oxide values in wt\%. Compositions of Apollo 14 black and Apollo 15 green glasses from Delano (1986) Ilmenite was provided by Dr. Nobu Shimizu and is from the Frank Smith mine, South Africa. Apollo 11 high $\mathrm{K}$ basalt composition from Beaty et al. (1979). Luna 24 composition from Grove (1978). 
Table 2. Conditions and results of experiments on synthetic analog of Apollo 14 black glass.

\begin{tabular}{ccccccc}
\hline Run \# & Pressure-GPa & Temperature- ${ }^{\circ} \mathrm{C}$ & Duration $(\mathrm{h})$ & Phases present & Proportions & $\sum \mathrm{r}^{2}$ \\
\hline B-162 & 2.18 & 1460 & 13 & gl,opx,sp & $1:$ tr:tr & - \\
B-166 & 1.70 & 1370 & 84 & gl,ol,opx,ilm & $75: 7: 14: 5$ & 0.5 \\
B-167 & 1.17 & 1370 & 22 & gl,ol,opx,sp & $87: 10: 2: 1$ & 0.4 \\
B-169 & 1.19 & 1400 & 31 & gl,ol & $94: 5$ & 1 \\
B-170 & 1.29 & 1385 & 44 & gl,ol,opx,sp & $91: 9:$ tr:tr & 0.2 \\
B-171 & 1.66 & 1425 & 14 & gl,ol,opx,sp & $94: 4: 2: t r$ & 0.2 \\
B-172 & 1.41 & 1420 & 18 & gl,ol,opx,sp & $90: 7: 3: t r$ & 0.5 \\
B-175 & 1.48 & 1450 & 5.5 & gl & - & - \\
B-176 & 2.22 & 1490 & 8.5 & gl & - & - \\
BPC-17 & 1.16 & 1390 & 24 & gl,ol,sp & $95: 4: 1$ & 0.4 \\
B-181 & 0.86 & 1420 & 24 & gl & - & - \\
B-182 & 1.48 & 1435 & 15 & gl & - & - \\
1 & 0.0001 & 1360 & 4.5 & gl,sp & $1: t r$ & - \\
2 & 0.0001 & 1375 & 3.5 & gl & - & - \\
3 & 0.0001 & 1400 & 3 & gl & - & - \\
\hline
\end{tabular}

Phase proportions determined by multiple linear regression of analyzed phases (Table 3 ) against staring composition (Table 1). tr indicates trace abundance. $(-)$ not determined.

to the $\mathrm{Fe}-\mathrm{FeO}$ buffer using the techniques discussed in the phase equilibria section.

\subsubsection{Experiments}

Experiments were performed in a piston cylinder device at 1 GPa pressure using the techniques described for the phase equilibria experiments. The run assembly uses a larger graphite capsule than employed for the phase equilibria experiments and does not contain a Pt outer capsule. Ilmenite disks were prepared by coring the ilmenite megacryst with a diamond coring bit $\left(0.11^{\prime \prime}\right.$ i.d.). The resulting core was sliced into disks, using a low-speed diamond wafering saw, and polished on 60()-grit sandpaper. Disks prepared by this technique were $0.7-1.5 \pm 0.04 \mathrm{~mm}$. The disk was sandwiched between equal sized layers of lunar magma composition (Fig. 2) in the graphite capsule. This sample geometry impedes convection within the charge

Table 3. Composition of run products in experiments on synthetic analog of Apollo 14 black glass.

\begin{tabular}{|c|c|c|c|c|c|c|c|c|c|c|c|c|c|c|c|c|c|c|c|c|c|c|c|}
\hline Run \# & phase & $\mathrm{N}$ & $\mathrm{MgO}$ & & $\mathrm{Al}_{2} \mathrm{O}_{3}$ & & $\mathrm{SiO}_{2}$ & & $\mathrm{CaO}$ & & $\mathrm{TiO}_{2}$ & & $\mathrm{Cr}_{2} \mathrm{O}_{3}$ & & Mno & & $\mathrm{FeO}$ & & $\mathrm{Na}_{2} \mathrm{O}$ & & $\mathrm{K}_{2} \mathrm{O}$ & & Total \\
\hline \multirow[t]{3}{*}{$\overline{B-162}$} & glass & 7 & 13.4 & 2.4 & 5.1 & 0.5 & 33.9 & 2.6 & 7 & 1 & 16.4 & 2.7 & 0.94 & 0.2 & 0.33 & 0.06 & 23.2 & 1.5 & 0.15 & 0.08 & 0.11 & 0.06 & 100.2 \\
\hline & & 8 & 27.5 & 0.4 & 2.9 & 0.3 & 53.2 & 0.5 & 1.64 & 0.06 & 0.95 & 0.1 & 1.12 & 0.1 & 0.21 & 0.02 & 13.4 & 0.1 & 0.03 & 0.03 & - & - & 100.9 \\
\hline & spin & 3 & 10.8 & 0.3 & 11.9 & 0.1 & 0.31 & 0.01 & 0.13 & 0.03 & 11.5 & 0.4 & 34.4 & 0.8 & 0.25 & 0.00 & 31.5 & 0.7 & & - & - & & 100.7 \\
\hline \multirow[t]{3}{*}{ B- 163} & glass & 7 & 11.1 & 0.2 & 5.41 & 0.05 & 32.4 & 0.3 & 8.2 & 0.1 & 19.1 & 0.1 & 0.89 & 0.03 & 0.27 & 0.04 & 21.0 & 0.3 & 0.21 & 0.04 & 0.13 & 0.01 & 98.7 \\
\hline & & 4 & 27.5 & 0.3 & 3.0 & 0.3 & 52.5 & 0.5 & 1.66 & 0.02 & 0.9 & 0.1 & & 0.07 & 0.22 & 0.01 & 13.4 & 0.3 & 0.04 & 0.01 & - & - & \\
\hline & spin & 3 & 10.1 & 0.2 & 12.6 & 0.1 & 0.28 & 0.02 & 0.07 & 0.00 & 9.3 & 0.2 & 38.0 & 0.6 & 0.27 & 0.01 & 30.1 & 0.5 & - & - & - & - & 100.7 \\
\hline \multirow[t]{4}{*}{ B-166 } & glass & 7 & 9.3 & 0.1 & 5.82 & 0.05 & 31.5 & 0.1 & 8.95 & 0.06 & 18.2 & 0.1 & 42 & 0.04 & 0.33 & 0.05 & 24.6 & 0.3 & 0.27 & 0.03 & 0.14 & 0.00 & 99.6 \\
\hline & & 3 & 37.2 & 0.09 & 0.11 & 0.03 & 37.7 & 0.1 & 0.31 & 0.01 & 0.22 & 0.03 & & 0.01 & 0.28 & 0.03 & 24.8 & 0.2 & & - & - & - & 100.9 \\
\hline & opx & 5 & 25.6 & 0.3 & 3.2 & 0.5 & 51.9 & 0.7 & 2.3 & 0.1 & 1.1 & 0.1 & 0.8 & 0.1 & 0.26 & 0.02 & 15.2 & 0.1 & 0.06 & 0.00 & - & - & 100.5 \\
\hline & ilm & 3 & 8.5 & 0.1 & 1.64 & 0.03 & 0.06 & 0.00 & 0.11 & 0.01 & 52.1 & 0.2 & 6.1 & 0.2 & 0.25 & 0.01 & 33.1 & 0.3 & - & - & - & & 101.9 \\
\hline \multirow[t]{4}{*}{ B-167 } & glass & 7 & 9.9 & 0.07 & 5.39 & 0.08 & 33.3 & 0.1 & 7.82 & 0.07 & 17.8 & 0.1 & 0.58 & 0.05 & 0.26 & 0.04 & 24.7 & 0.2 & 0.15 & 0.04 & 0.12 & 0.01 & 100.0 \\
\hline & ol & 4 & 38.7 & 0.08 & 0.07 & 0.01 & 37.8 & 0.0 & 0.24 & 0.01 & 0.24 & 0.02 & 0.24 & 0.02 & 0.24 & 0.01 & 23.9 & 0.1 & - & - & - & & 101.4 \\
\hline & opx & 6 & 27.4 & 0.1 & 2.2 & 0.2 & 52.4 & 0.3 & 1.56 & 0.04 & 1.19 & 0.07 & 0. & 0.04 & 0.22 & 0.05 & 14.4 & 0.1 & 0.02 & 0.01 & - & - & 100.3 \\
\hline & spin & 4 & 10.0 & 0.3 & 8.8 & 0.2 & 0.13 & 0.03 & 0.08 & 0.03 & 16.7 & 0.2 & 29.5 & 0.2 & 0.30 & 0.01 & 5.9 & 0.2 & - & - & - & & 101.4 \\
\hline \multirow[t]{2}{*}{ B-169 } & glass & 7 & 11.3 & 0.1 & 5.16 & 0.05 & 34.33 & 0.20 & 7.32 & 0.05 & 16.5 & 0.1 & 0.81 & 0.07 & 0.24 & 0.04 & 24.0 & 0.2 & 0.18 & 0.05 & 0.11 & 0.01 & 99.7 \\
\hline & ol & 4 & 39.7 & 0.2 & 0.08 & 0.05 & 38.05 & 0.04 & 0.22 & 0.01 & 0.17 & 0.01 & 0.26 & 0.01 & 0.22 & 0.03 & & 0.2 & - & - & - & - & 101.1 \\
\hline \multirow[t]{4}{*}{ B- 170} & glass & 7 & 10.7 & 0.4 & 5.34 & 0.03 & 33.9 & 0.1 & 7.60 & 0.08 & 17.4 & 0.3 & 0.71 & 0.03 & 0.34 & 0.03 & 24.3 & 0.2 & 0.19 & 0.05 & 0.11 & 0.01 & 100.2 \\
\hline & ol & 4 & 38.6 & 0.2 & 0.08 & 0.00 & 37.9 & 0.2 & 0.25 & 0.01 & 0.16 & 0.02 & 0.27 & 0.05 & 0.20 & 0.04 & 23.6 & 0.1 & - & - & - & - & 101.0 \\
\hline & opx & 4 & 27.0 & 0.2 & 2.45 & 0.06 & 52.6 & 0.2 & 1.62 & 0.03 & 1.14 & 0.02 & 1.00 & 0.08 & 0.21 & 0.00 & 14.2 & 0.1 & 0.02 & 0.02 & - & - & 100 \\
\hline & spin & 4 & 9.8 & 0.08 & 9.19 & 0.07 & 0.22 & 0.07 & 0.08 & 0.02 & 16.0 & 0.1 & 32.8 & 0.2 & 0.28 & 0.01 & 33.4 & 0.3 & - & - & - & 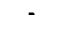 & 101.8 \\
\hline \multirow[t]{4}{*}{ B-171 } & glass & 7 & 11.7 & 0.08 & 5.06 & 0.03 & 33.1 & 0.1 & 7.29 & 0.02 & 16.8 & 0.1 & 0.75 & 0.05 & 0.25 & 0.05 & 24.7 & 0.2 & 0.20 & 0.03 & 0.13 & 0.01 & 99.5 \\
\hline & ol & 7 & 40.3 & 0.1 & 0.09 & 0.01 & 37.9 & 0.2 & 0.23 & 0.01 & 0.25 & 0.01 & & 0.0 & 0.25 & 0.01 & 21 & 0.3 & & - & & - & 100.7 \\
\hline & opx & 4 & 28.2 & 0.3 & 2.3 & 0.4 & 52.6 & 0.4 & 1.46 & 0.04 & 1.06 & 0.12 & 1.01 & 0.15 & 0.18 & 0.01 & 13.1 & 0.1 & 0.01 & 0.01 & - & - & 99.9 \\
\hline & spin & 2 & 11.0 & 0.10 & 10.0 & 0.1 & 0.26 & 0.00 & 0.13 & 0.00 & 12.9 & 0.1 & 34.0 & 0.0 & 0.26 & 0.01 & 31.5 & 0.0 & - & - & & - & 100.1 \\
\hline \multirow[t]{4}{*}{ B- 172} & glass & 7 & 10.8 & 0.04 & 5.24 & 0.04 & 33.2 & 0.2 & 7.62 & 0.05 & 17.4 & 0.1 & 0.64 & 0.04 & 0.26 & 0.07 & 25.1 & 0.3 & 0.26 & 0.05 & 0.13 & 0.01 & 100.2 \\
\hline & ol & 3 & 39.1 & 0.3 & 0.08 & 0.02 & 38.1 & 0.1 & 0.23 & 0.00 & 0.17 & 0.03 & & 0.02 & 0.23 & 0.02 & & 0.1 & - & - & - & & \\
\hline & $o p$ & 5 & 27.7 & 0.2 & 2.34 & 0.09 & 52 & 0.2 & 1.46 & 0.01 & 1.09 & 0.05 & & 0.05 & 0.20 & 0.01 & 13.7 & 0.2 & 0.00 & 0.00 & - & - & 100.2 \\
\hline & spin & 3 & 10.1 & 0.10 & 9.10 & 0.07 & 0.00 & 0.00 & 0.14 & 0.00 & 15.2 & 0.1 & 31 & 0.0 & 0.37 & 0.01 & 34.4 & 0.0 & - & - & - & - & 100.4 \\
\hline \multirow[t]{3}{*}{ BPC -17} & glass & 7 & 12.0 & 0.08 & 5.02 & 0.04 & 34 & 0.2 & 7.25 & 0.05 & 16.4 & 0.1 & 0. & 0.04 & 0.28 & 0.07 & 24.3 & 0.2 & 0.20 & 0.04 & 0.12 & 0.01 & 99.9 \\
\hline & ol & 3 & 40.1 & 0.1 & 0.07 & 0.02 & 38.3 & 0.3 & 0.22 & 0.01 & 0.17 & 0.03 & 0.29 & 0.02 & 0.23 & 0.04 & 21.4 & 0.1 & - & - & - & - & 100.8 \\
\hline & spin & 3 & 10.3 & 0.1 & 7.35 & 0.07 & 0.00 & 0.00 & 0.14 & 0.00 & 14.5 & 0.1 & 35.5 & 0.0 & 0.35 & 0.01 & 32.3 & 0.0 & & 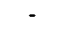 & - & - & 100.4 \\
\hline
\end{tabular}

Oxide values in wt \%. Reported value is average of $\mathrm{N}$ points, number after oxide is 1 standard deviation on average. $(-)$ indicates concentration not determined. 


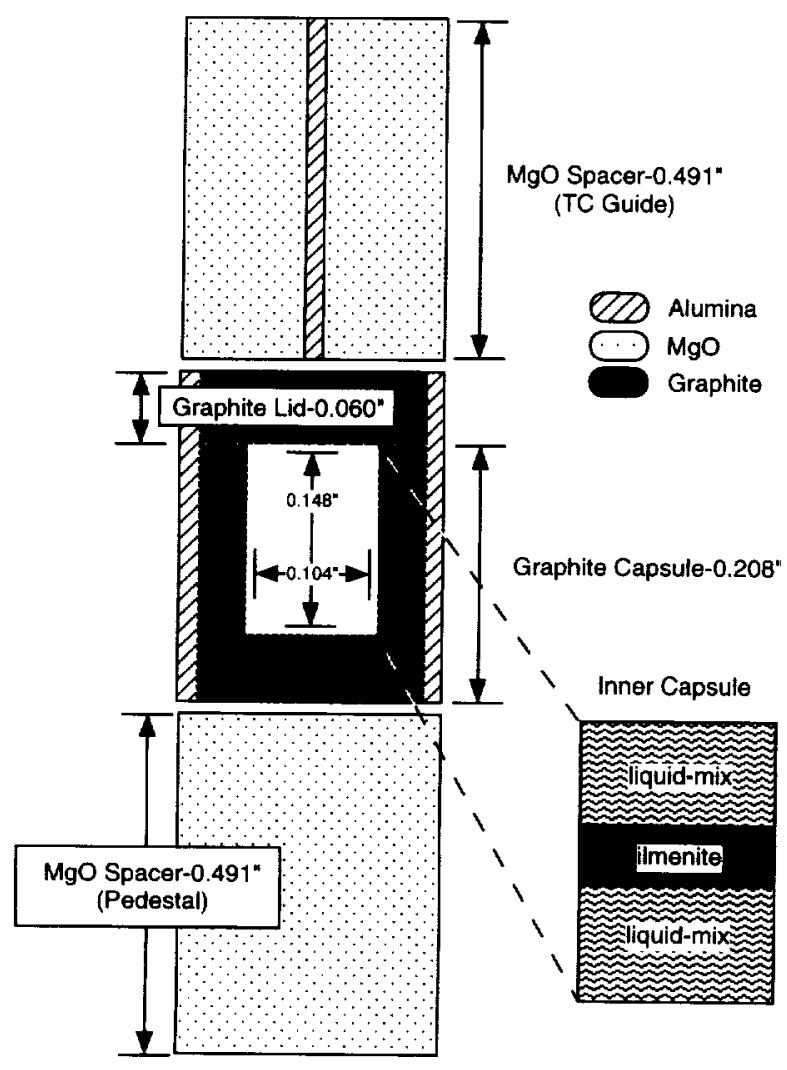

Fig. 2. Assembly used for ilmenite dissolution experiments carried out in the piston cylinder apparatus. Ilmenite disk is centered in the hot spot of the furnace, and the furnace is surrounded by $\mathrm{BaCO}_{3}$ pressure medium.

(Zhang et al., 1989). The ilmenite disk and capsule form a tight fit to prevent movement of the disk during the experiment.

Experiments were run at a variety of temperatures and durations to determine the temperature and time dependence of dissolution rate (Table 4). Four different magma compositions were selected to allow for near-liquidus experiments to be performed at each temperature and note the effect of melt $\mathrm{TiO}_{2}$ content on dissolution rate. Most experimental products consist of liquid plus the ilmenite disk; some also contain phenocrysts of $\mathrm{Cr}$-ulvospinel, olivine, or pigeonite ( phase appearances in Table 4, compositions in Table 5). The thickness of the ilmenite disk in the experiments was determined using a Zeiss reflected light microscope with an ocular scale accurate to $\pm 10-\mu \mathrm{m}$.

\subsection{Analytical Methods}

The experimental products were analyzed by electron microprobe at the Massachusetts Institute of Technology on a JEOL $733 \mathrm{Su}$ perprobe using wavelength-dispersive techniques. Data were reduced using the correction scheme of Bence and Albee (1968) with the modifications of Albee and Ray (1970). Crystalline phases in the experiments were analyzed at $15-\mathrm{kV}$ accelerating potential, 10-n A beam current, and a spot size on the order of $2-\mu \mathrm{m}$. Spot size was increased to $10-\mu \mathrm{m}$ for glass analyses in order to minimize diffusion of alkali elements away from the region of interest during the analysis.

\section{EXPERIMENTAL RESULTS}

\subsection{Results of Phase Equilibria Experiments}

The liquidus of the synthetic Apollo 14 black glass (Fig. 3 ) was determined up to $2.2-\mathrm{GPa}$. At 1 -atm the liquidus phase is chrome-ulvospinel ( $\mathrm{Cr}$-usp). From about 0.5 to 1.5 $\mathrm{GPa}$, olivine (ol) replaces $\mathrm{Cr}$-usp as the liquidus phase. The black glass is cosaturated with ol, low-Ca pyroxene (opx), and $\mathrm{Cr}$-usp at $1.5-\mathrm{GPa}$ and $1430^{\circ} \mathrm{C}$. At pressures above 1.7$\mathrm{GPa}$, the liquidus is saturated with opx and $\mathrm{Cr}$-usp. The liquidus is notably lacking ilmenite. Ilmenite does appear as a subliquidus phase in one experiment approximately $70^{\circ}$ below the liquidus and is separated from the liquidus by a Cr-usp stability field. Our study represents the first on the Apollo 14 composition. Two other high-Ti lunar ultramafic glass compositions have been studied at elevated pressure: Apollo 17 Orange Glass (Green et al., 1975) and Apollo 15 Red Glass (Delano, 1980; Kesson, 1975). The experiments of Green et al. ( 1975 ) and Kesson (1975) should be considered reconnaissance in nature. Green et al. (1975) found ilmenite as a near solidus phase in experiments carried out on Apollo 17 orange glass. No information is provided on the container used, the duration of the experiment, the oxidation state of the experimental material, or whether the experimental products interacted with their enclosing containers. Delano (1980) carried out a careful study of the Apollo 15 red glass and also observed ilmenite near the solidus and found that a higher-temperature Cr-usp stability field separated the ilmenite field from the liquidus.

\subsection{Results of Ilmenite Dissolution Experiments}

Ilmenite dissolution rate experiments performed over the temperature range of $1550-1270^{\circ} \mathrm{C}$ using synthetic analogs

Table 4. Conditions and results of ilmenite dissolution rate experiments. Pressure $=1 \mathrm{GPa}$ for all experiments.

\begin{tabular}{cccccccc}
\hline Exp\# & Liquid composition & Temperature ${ }^{\circ} \mathrm{C}$ Initial length $(\mathrm{cm})$ & Final length $(\mathrm{cm})$ & Duration $(\mathrm{sec})$ & Dissolution rate $(\mathrm{cm} / \mathrm{sec})$ & Phases present \\
\hline 49 & Apollo 15 green glass & 1450 & $0.074 \pm 3$ & $0.038 \pm 1$ & 255 & $1.41 \mathrm{E}-04$ & lq+ilm \\
50 & Apollo 15 green glass & 1400 & $0.107 \pm 3$ & $0.099 \pm 3$ & 375 & $2.23 \mathrm{E}-05$ & lq+ilm \\
51 & Apollo 15 green glass & 1450 & $0.086 \pm 4$ & $0.026 \pm 2$ & 1800 & $3.35 \mathrm{E}-05$ & Iq+ilm+Cr-usp+ol \\
52 & Apollo I5 green glass & 1350 & $0.070 \pm 1$ & 0.050 & 1800 & $1.09 \mathrm{E}-05$ & lq+ilm+Cr-usp+ol+pig \\
53 & Apollo 15 green glass & 1550 & $0.081 \pm 1$ & 0.000 & 480 & $1.69 \mathrm{E}-04$ & lq+Cr-usp \\
54 & Apollo 14 black glass & 1450 & $0.074 \pm 4$ & $0.027 \pm 1$ & 1800 & $2.59 \mathrm{E}-05$ & lq+ilm+Cr-usp \\
66 & Apollo 11 high-K & 1270 & $0.077 \pm 4$ & $0.074 \pm 4$ & 5700 & $5.88 \mathrm{E}-07$ & lq+ilm \\
67 & Luna 24 & 1270 & $0.156 \pm 4$ & $0.148 \pm 8$ & 5580 & $1.49 \mathrm{E}-06$ & $1 \mathrm{q}+\mathrm{ilm}$ \\
68 & Luna 24 & 1270 & $0.076 \pm 1$ & $0.058 \pm 2$ & 18960 & $9.78 \mathrm{E}-07$ & lq+ilm \\
\hline
\end{tabular}

All experiments at $1-\mathrm{GPa}$. 
Table 5. Crystalline phases in some ilmenite dissolution rate experiments.

\begin{tabular}{|c|c|c|c|c|c|c|c|c|c|}
\hline Phase & $\mathrm{MgO}$ & $\mathrm{Al}_{2} \mathrm{O}_{3}$ & $\mathrm{SiO}_{2}$ & $\mathrm{CaO}$ & $\mathrm{TiO}_{2}$ & $\mathrm{Cr}_{2} \mathrm{O}_{3}$ & $\mathrm{MnO}$ & $\mathrm{FeO}$ & $\mathrm{NiO}$ \\
\hline \multicolumn{10}{|c|}{ Experiment \#51 } \\
\hline olivine & 43.6 & 0.07 & 39.3 & 0.20 & 0.29 & 0.25 & 0.07 & 15.0 & 0.23 \\
\hline chromian-ulvospinel & 15.9 & 4.82 & 0.11 & 0.08 & 31.8 & 11.0 & 0.10 & 36.0 & 0.39 \\
\hline chromian-ulvospinel & 15.8 & 4.80 & 0.15 & 0.07 & 31.8 & 11.0 & 0.20 & 36.3 & 0.34 \\
\hline ilmenite disk & 13.5 & 0.78 & 0.03 & 0.06 & 58.3 & 1.70 & 0.13 & 26.2 & 0.17 \\
\hline exsolution lamellae & 13.6 & 1.78 & 0.15 & 0.02 & 38.4 & 2.57 & 0.23 & 44.2 & 0.25 \\
\hline \multicolumn{10}{|c|}{ Experiment \#54 } \\
\hline chromian-ulvospinel & 14.8 & 3.71 & 0.17 & 0.05 & 30.0 & 15.4 & 0.23 & 35.7 & 0.17 \\
\hline ilmenite disk & 12.7 & 0.65 & 0.04 & 0.07 & 57.8 & 2.72 & 0.16 & 26.8 & 0.13 \\
\hline
\end{tabular}

Values in wt\%

of low- and high-Ti lunar melt compositions are summarized in Fig. 4. As expected, ilmenite dissolution rate increases as temperature increases. Measured dissolution rate decreases with increased run duration and as melt $\mathrm{TiO}_{2}$ increases in the liquid at the ilmenite-melt interface. The ilmenite disk completely dissolved in the super-liquidus. $1550^{\circ} \mathrm{C}$ experiment in low-Ti Apollo 15 green glass within the 480-sec duration of the experiment, hence the reported dissolution rate is a minimum value, indicated by the vertical arrow and question mark in Fig. 4. Of the three experiments performed at $1450^{\circ} \mathrm{C}$, two used low-Ti Apollo 15 green glass and varied run duration (255- and 1800-sec). In the 1800-sec experiment, over $65 \%$ of the disk dissolved and the disk lost contact with the sides of the capsule and sank to the bottom. Minor amounts of Cr-usp and olivine crystallized in this experiment (Table 5). The Cr-usp phenocrysts are $\sim 10-\mu \mathrm{m}$ in size and are found suspended in a thin layer $(\sim 100-\mu \mathrm{m})$ around the ilmenite disk (Fig. 5). Olivine phenocrysts are found in a thin layer near the top of the charge. Olivine is $\mathrm{Fo}_{x 4}$ and its floatation indicates that the melt had a density $>3.37-\mathrm{g} / \mathrm{cm}^{3}$.

A third experiment performed at $1450^{\circ} \mathrm{C}$ used high-Ti AP 14 black glass liquid. This experiment was run for $1800-\mathrm{sec}$ and has a slightly slower (Fig. 4) dissolution rate than the equivalent experiment with low-Ti AP 15 green glass liquid.

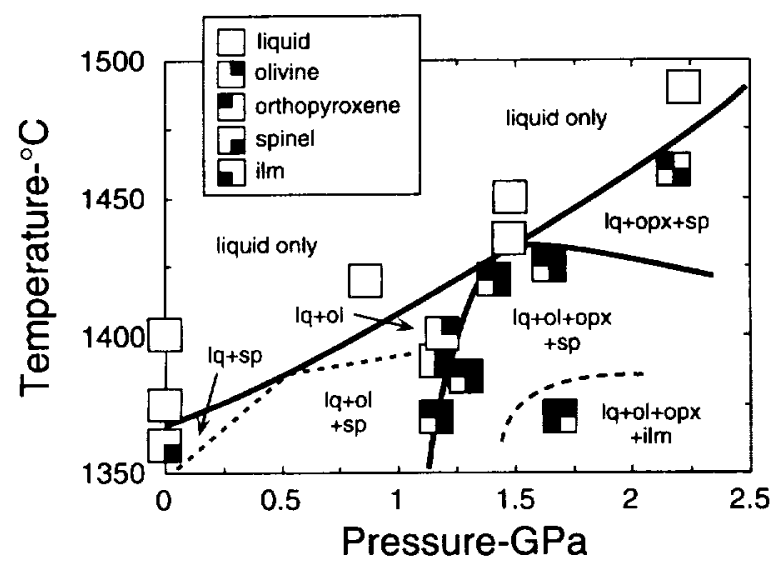

Fig. 3. Phase diagram of synthetic analog of Apollo 14 black glass. Dalta from Table 2.
The end products of the Apollo 14 black glass liquid experiment were similar to those produced in the 1800-sec AP 15 green glass liquid experiment. Dissolution proceeded to about the same extent and the ilmenite disk sank to the bottom of the charge. Cr-usp phenocrysts (Table 5 ) precipitated in a layer around the ilmenite. The liquids in both of the 1800 -sec, $1450^{\circ} \mathrm{C}$ experiments (Apollo 15 green and Apollo 14 black glass liquids ) vary in $\mathrm{TiO}_{2}$ content from 32 wt\% near the ilmenite disk to $24 \mathrm{wt} \%$ near the upper part of the charge.

Dissolution experiments at subliquidus temperatures for Apollo 15 green glass liquid contained the ilmenite disk and minor olivine crystals at $1400^{\circ} \mathrm{C}$ and olivine and pigeonite crystals at $1350^{\circ} \mathrm{C}$. Experiments performed at $1270^{\circ} \mathrm{C}$ using low- and high-Ti mare basalts were near liquidus and contained no crystalline phases aside from the ilmenite disk. The results of the $1270^{\circ} \mathrm{C}$ experiments show similar relations to the higher temperature experiments. Dissolution rate can be described by a linear relation in square root of time vs. dissolved distance. As initial liquid Ti-content increases, dissolution rate decreases.

The data points from all of the experiments were fit to an Arrhenius relationship:

$$
\begin{aligned}
& \text { Dissolution rate }=\left(1.5432 * 10^{17}\right) * \mathrm{e}^{10.01476 .7 * \text { Temperaure }} ; \\
& \qquad R^{2}=0.64541 .
\end{aligned}
$$

This fit is shown in Fig. 4. Although the expression averages a small, but real variability in dissolution rate that results from variation in liquid composition, it is considered adequate for comparison with results of other dissolution rates and for testing the assimilation models developed below.

Several characteristics of the experiments indicate that ilmenite dissolution is controlled by diffusive mass transport in the liquid (Cooper, 1962). Plots of the thickness of the dissolved ilmenite layer vs. square root of time are linear (data in Table 4). The linear relation is best defined in the $1270^{\circ} \mathrm{C}$ experiments. The 1400 and $1450^{\circ} \mathrm{C}$ experiments and the single experiment at $1550^{\circ} \mathrm{C}$ show a square root of time vs. dissolution distance dependence. This square root of time vs. distance dependence is consistent with a diffusion-controlled, temperature-activated process. The scatter present in the 1400 and $1450^{\circ} \mathrm{C}$ dissolution rate composition vs. dis- 


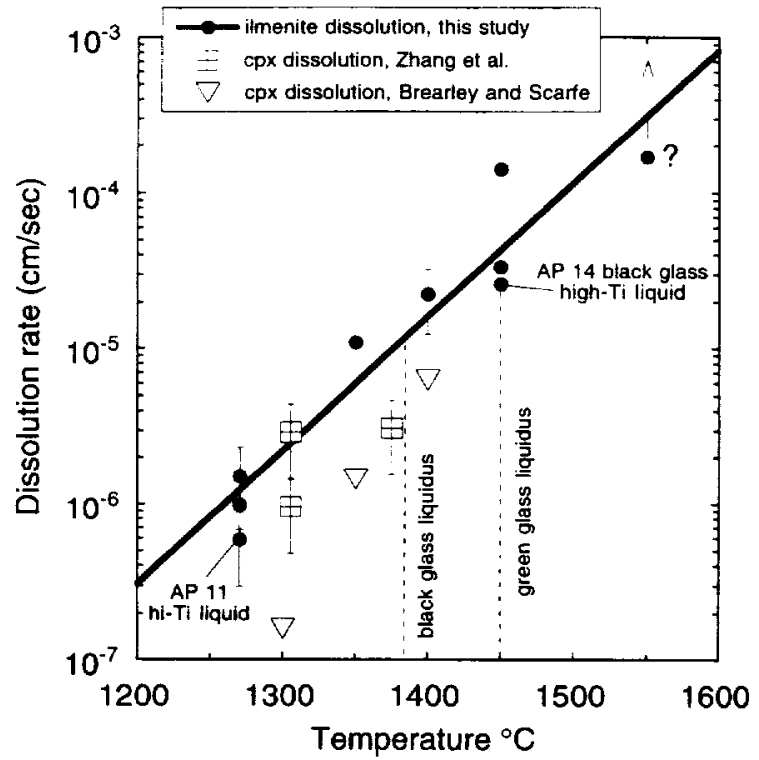

Fig. 4. Results of dissolution rate experiments. All experiments performed on low-Ti liquids except those noted. Clinopyroxene dissolution rate data from Brearley and Scarfe (1986) and Zhang et al. (1989).

tance profiles probably results from the rapid dissolution rates at these temperatures, and from the complication that some dissolution occurs as the experiment approaches the run conditions. The observed decrease in dissolution rate as $\mathrm{TiO}_{2}$ at the interface increases is also consistent with a melt diffusion control.

Several complicating effects operate during ilmenite dissolution. Free convection at the interface occurs when the dense, high-Ti melt becomes unstable with respect to the adjacent lower density, low-Ti melt. Figure 5 shows these effects in two of the dissolution experiments. Both show a boundary layer that consists of a high-Ti liquid (Fig. 6) and Cr-usp crystals. This dense boundary layer is trapped on the top of the dissolving ilmenite disk, but convective instabilities develop nonetheless and transfer high-Ti melt into the overlying low-Ti layer. One plume is visible in the upper left of the upper layer in Fig. 5b. Below the ilmenite disk, dense, high-Ti melt descends into and mixes with low-Ti melt. Plumes of descending high-Ti liquid are evident in both dissolution experiments. Figure 6 shows the compositional variations in the boundary layer that forms at the top interface of the ilmenite disk. This layer varies from 0.3 to 0.15 $\mathrm{mm}$ in thickness and is present in all experiments, even in those of long duration (e.g., BPC-67). The compositional variation does not resemble that of a diffusion profile. Mass transfer is rapid and may be driven by instabilities induced by the large density difference between the high-Ti and low$\mathrm{Ti}$ melts. Dissolution produces a zone of high-Ti melt $+\mathrm{Cr}-$ usp, which shows a sharp compositional gradient at its exterior contact with low-Ti melt. On the bottom of the ilmenite disk, the dense high-Ti melt $+\mathrm{Cr}$-usp mix with the underlying liquid as the ilmenite dissolves. Estimation of the fraction of ilmenite disk dissolved on the top and bottom is possible in several experiments and indicates that the differences in dissolution rates between top and bottom are indistinguishable.

These complications indicate that mass transfer in the melt was not solely by chemical interdiffusion. However, similar complexities are likely to have operated in the lunar interior when a low-Ti magma interacted with ilmenite-bearing cumulates. Low-Ti melts that rise from depth and infiltrate high-Ti cumulates would interact with the dissolving cumulates in a manner analogous to the dissolution and mixing processes that occur in the bottom portion of the dissolution experiments. Thus, we judge the experimental results to be relevant to the problem of petrogenesis of high-Ti magmas by assimilation.
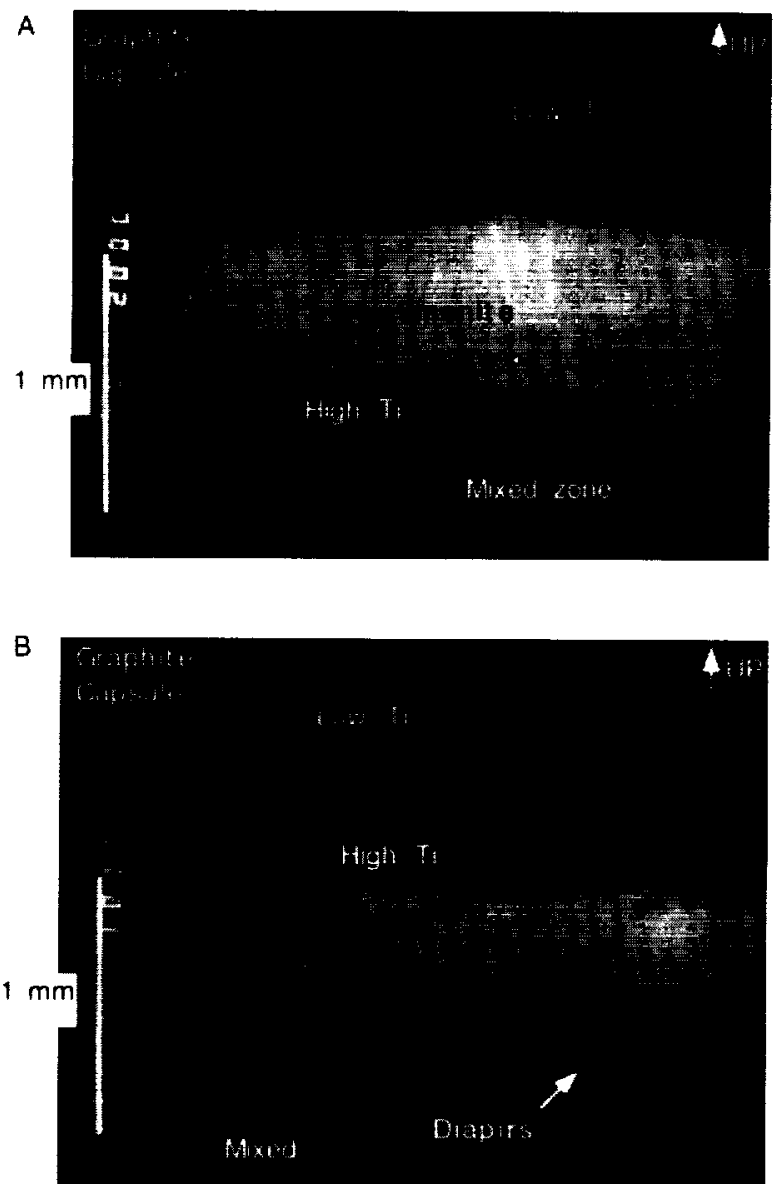

Fig. 5. Backscattered electron micrographs of products of dissolution of ilmenite in Apollo 15 green glass liquid. Experiments BPC-49 and BPC-52 are shown. Bright rectangle is ilmenite surrounded by a high-Ti melt $+\mathrm{Cr}$-usp boundary layer. Dark borders are edges of the graphite container. Gray levels in surrounding quenched glass (with quench crystals) reflect variations in $\mathrm{TiO}$. content. In both experiments convective instabilities are homogenizing the melts below the ilmenite disk. Above the disk, the highTi melt is trapped in a boundary layer. In BPC-49 the low and high-Ti melts are separated by al dark crack that formed during sample preparation. 

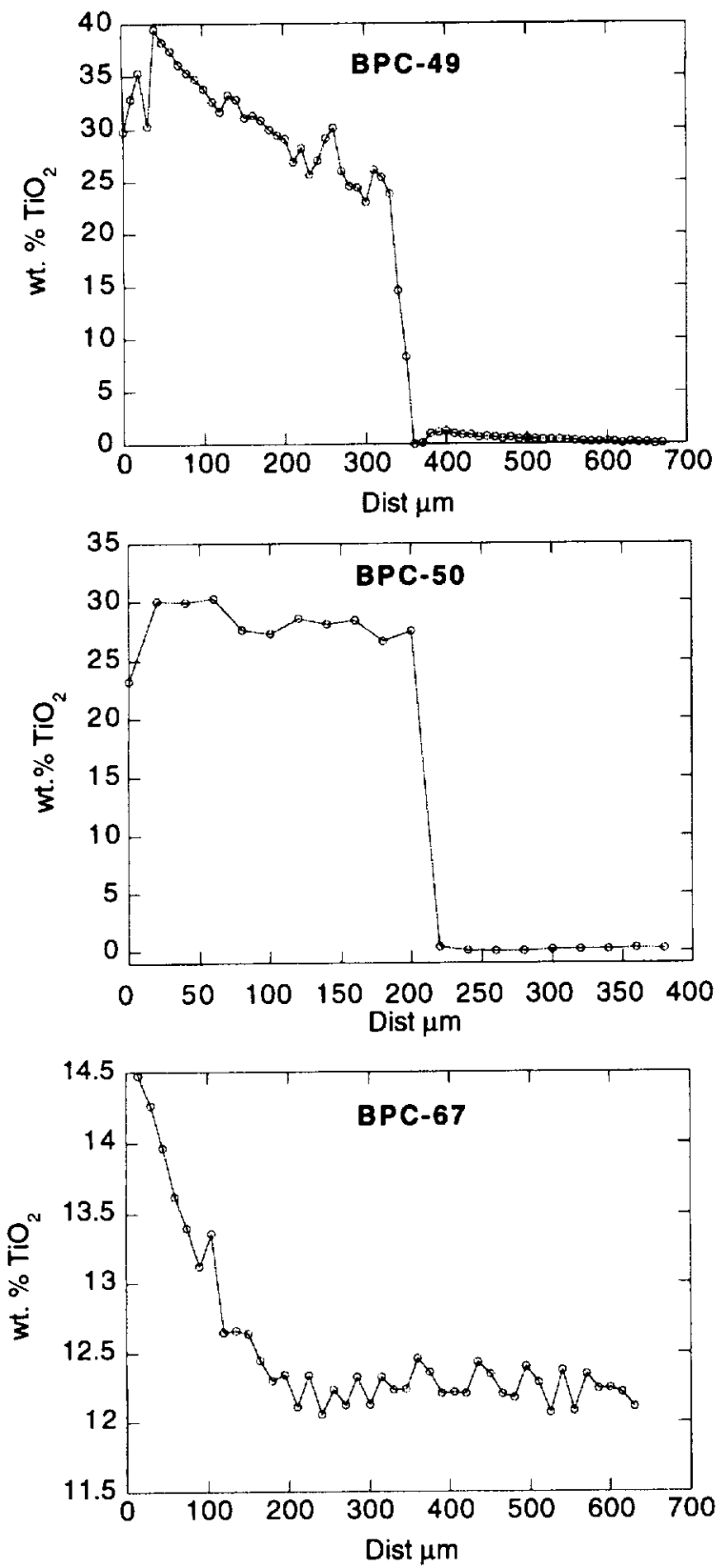

Fig. 6. TiO, content of liquid in dissolution rate experiments as a function of distance from the ilmenite disk. Profiles are from melt trapped above the ilmenite disk. Numbers refer to experiments in Table 4 .

\section{DISCUSSION}

\subsection{Formation of Lunar Magmas}

\subsubsection{Cumulate remelting model}

It was initially proposed that low-Ti magmas formed by remelting of the deep Ti-poor cumulates, while high-Ti magmas formed by remelting of the shallow, Ti-rich cumulates. This model offered a straightforward explanation of the broad compositional diversity of lunar magmas and was consistent with the results of experimental studies of the mare basalts. Experimental melting studies of low-Ti mare basalts showed them to be liquidus cosaturated with of + opx at pressures indicating depths of segregation at $200-40()-\mathrm{km}$ (Green et al., 1971 and Grove et al., 1973), similar to the proposed depth of ol \pm low-Ca pyroxene cumulates. HighTi mare basalts showed liquidus cosaturation with ilmenite, $\mathrm{cpx}$, and spinel at pressures indicating depths of $\sim 10(0) \mathrm{km}$ (Longhi et al., 1974), similar to the depth of the proposed ilmenite-bearing cumulates.

\subsubsection{Inconsistencies with cumulate remelting model}

The simple cumulate remelting model, however, proved inconsistent with experimental studies of ultramatic glass compositions (summarized in Table 6), which provide inherently better choices for lunar primary magmas than mare basalts (Delano, 1986). First of all, the high-Ti ultramatic glasses are not saturated on their liquidus with ilmenite at any pressure. The Apollo 14 black glass is the most Tirich ultramafic glass and is not near liquidi saturation with ilmenite (Fig. 3). It does have $\mathrm{Cr}$-usp on its liquidus that

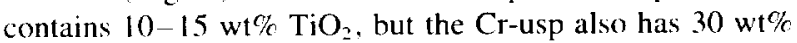
$\mathrm{Cr}_{2} \mathrm{O}_{3}$ and, therefore, could not be present in significant abundance in the lunar interior. Studies of the Apollo 15 red glass, the ultramafic glass second highest in $\mathrm{Ti}$, show similar liquidus relations (Kesson, 1975; Delano, 1980). The dissolution rate experiments also show that the Apollo 14 black glass composition is very far from saturation with ilmenite. These experiments produced liquids with over $30 \mathrm{wt} \% \mathrm{TiO}_{2}$ (run \#54, Fig. 6) that are not ilmenite saturated.

Secondly, both low- and high-Ti ultramafic glass compositions are cosaturated with ol and opx on their liquidus in the pressure range of 1.5-2.5-GPa, with no relationship between $\mathrm{TiO}_{2}$ content and pressure of multiple saturation (Table 6 ). This has been interpreted to indicate that both low- and highTi magmas are derived from melting of similar deep. mafic magma ocean cumulates at depths between $300-500-\mathrm{km}$. This depth is well below the $<100-\mathrm{km}$ depth predicted for the late stage. ilmenite-bearing cumulate layers.

\subsubsection{Cumulate overtum model}

A possible resolution to the second problem is that the lunar cumulate pile overturns and mixes the ilmenite-bearing layer (Ringwood and Kesson, 1976), or melts of the ilmenite-bearing layer (Hess and Parmentier, 1995), with the lowTi magma source. A number of physical models of the magma ocean cumulate pile support this large-scale overturn event (Herbert, 1980; Spera, 1992; Hess and Parmentier. 1995).

\subsubsection{Inconsistencies with cumulate overturn model}

There are a number of arguments against the cumulate overturn models. The first is that the physical models of the cumulate pile that show overturn require that the ilmenite-bearing layer is very thick, $5-10 \%$ of the total magma ocean (Spera. 1992: Hess and Parmentier, 1995 ). 
Table 6. Temperature and pressure of liquidus saturation with olivine and low-Ca pyroxenc.

\begin{tabular}{cccccc}
\hline Mission & Glass type & $\mathrm{TiO}_{2}$ (wt.\%) & Temperature ${ }^{\circ} \mathrm{C}$ & Pressure (GPa) & Reference \\
\hline Apollo 15 & green & 0.26 & 1525 & 2.0 & 1 \\
Apollo 14 & VLT & 0.55 & 1520 & 2.2 & 2 \\
Apollo 17 & VLT & 0.63 & 1500 & 1.8 & 3 \\
Apollo 17 & orange & 9.12 & 1482 & 2.2 & 4 \\
Apollo 15 & red & 13.8 & 1463 & 2.5 & 5 \\
Apollo 14 & black & 16.4 & 1430 & 1.5 & This study \\
\hline
\end{tabular}

Temperature and pressure of olivine and opx multiple saturation for ultramafic glass compositions. Data: (1) T. L. Grove, unpubl., (2) Chen and Lindsley (1983), (3) Chen et al. (1982), (4) Green et al. (1975), and (5) Delano (1980).

Snyder et al. ( 1992) argue that this is unreasonably thick because ilmenite precipitation would likely initiate small, localized convection. The density anomaly of an ilmenitebearing layer would thus be smeared out across a thicker. less dense layer than that required by overturn models. Another argument against the overturn models is the strong correlation between $\mathrm{TiO}_{2}$ content and temperature of liquidus saturation with ol + opx (Fig. 7). The AP 14 black and AP 15 red glasses have the lowest liquidus temperatures, but define the low- and high-pressure extremes of ol + opx liquidus saturation for both low and high-Ti ultramafic glass compositions (Table 6). If the overturn model were correct, this would indicate a negative temperature vs. depth profile.

The final and strongest argument against formation of high-Ti magmas by the lunar overturn model is that the high compressibilities and densities of high- $\mathrm{Ti}$ magmas would prevent their eruption if they were produced at similar depths to the low-Ti magmas. Delano (1990) calculated that highTi compositions would become denser than their crystalline surroundings at relatively modest pressures. Agee and Circone (1995) have confirmed this result with falling sphere experiments that show that Apollo 14 black glass liquids

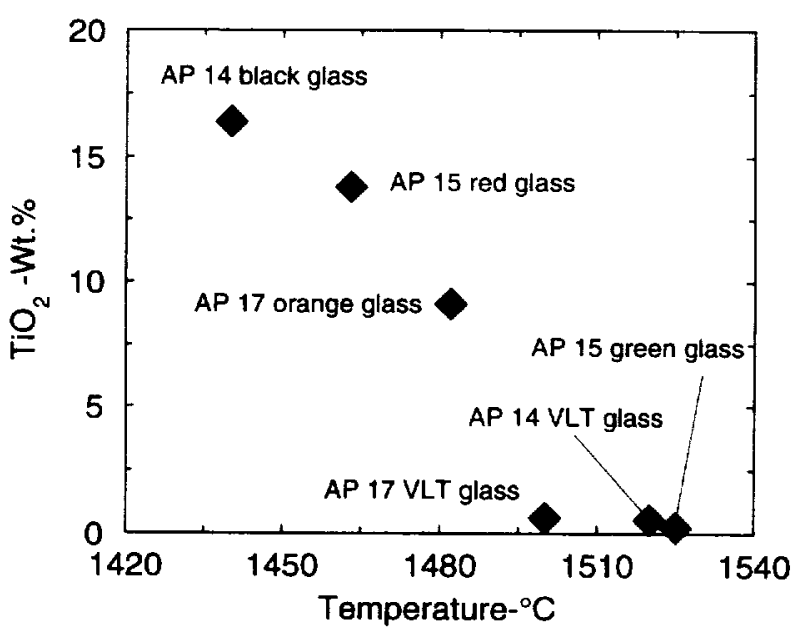

Fig. 7. Plot of $\mathrm{TiO}_{2}$ in wt\% against the temperature of liquidus cosaturation with olivine and low-Ca pyroxene. Data from this study, Green et al. (1975); Delano (1980); Chen et al. (1982); Chen and Lindsley (1983). would become denser than olivine and low-Ca pyroxene cumulates at pressures corresponding to 200-300-km depth. Consequently, if the ilmenite layer sank and enriched the source in $\mathrm{Ti}$, melts of these regions would sink into the deep lunar interior rather than erupt on the surface. Hess (1991) proposed a way to overcome this problem through partial crystallization and entrainment of high-Ti liquid in ascending diapirs.

Alternatively, some process besides melting could take place during lunar magma formation. If the lunar magma source is at $300-500-\mathrm{km}$ depth, magmas must ascend significantly farther through the lunar mantle to erupt than terrestrial magmas must travel through the Earth's mantle. It is possible that some processing takes place en route that alters lunar magma compositions. If this process is responsible for generating the range in $\mathrm{TiO}_{2}$ contents observed in lunar magmas, its characteristics are as follows: (1) it increases liquid $\mathrm{TiO}_{2}$ content; (2) it lowers liquidus temperature; and ( 3 ) it produces liquids that are not in equilibrium with a very high-Ti phase. Assimilation of the Ti-rich, ilmenite-bearing cumulates by low-Ti primary magmas is compatible with all of these characteristics. Assimilation of Ti-rich cumulates would increase magmatic $\mathrm{TiO}_{2}$ content, while decreasing liquidus temperature as it drops to supply the heat of fusion for assimilation. In addition, the assimilating liquid is not required to come to equilibrium with the ilmenite assimilant and thus may not be near saturation with it in experimental studies.

\subsection{Assimilation Model for High-Ti Magma Genesis}

An assimilation origin for high-Ti mare basalts was initially proposed by Anderson (1971), who suggested that high-Ti magmas were derived from low-Ti primary magmas that assimilated armalcolite at subcrustal depths. This model proved inconsistent with studies of armalcolite stability (Kesson and Lindsley, 1976). The assimilation model was revived by Hubbard and Minear (1975) who proposed that high-Ti magmas were produced by selective assimilation of the ilmenite and clinopyroxene bearing magma ocean cumulates into low-Ti primary magmas. Ringwood and Kesson (1976) rejected this model based on the assumptions that: (1) ilmenite and clinopyroxene would be assimilated in the proportions in which they are present and (2) the only heat available for assimilation is that provided by the latent heat of crystallization. We argue below that these assump- 
Table 7. Mass balance calculations for assimilation reaction

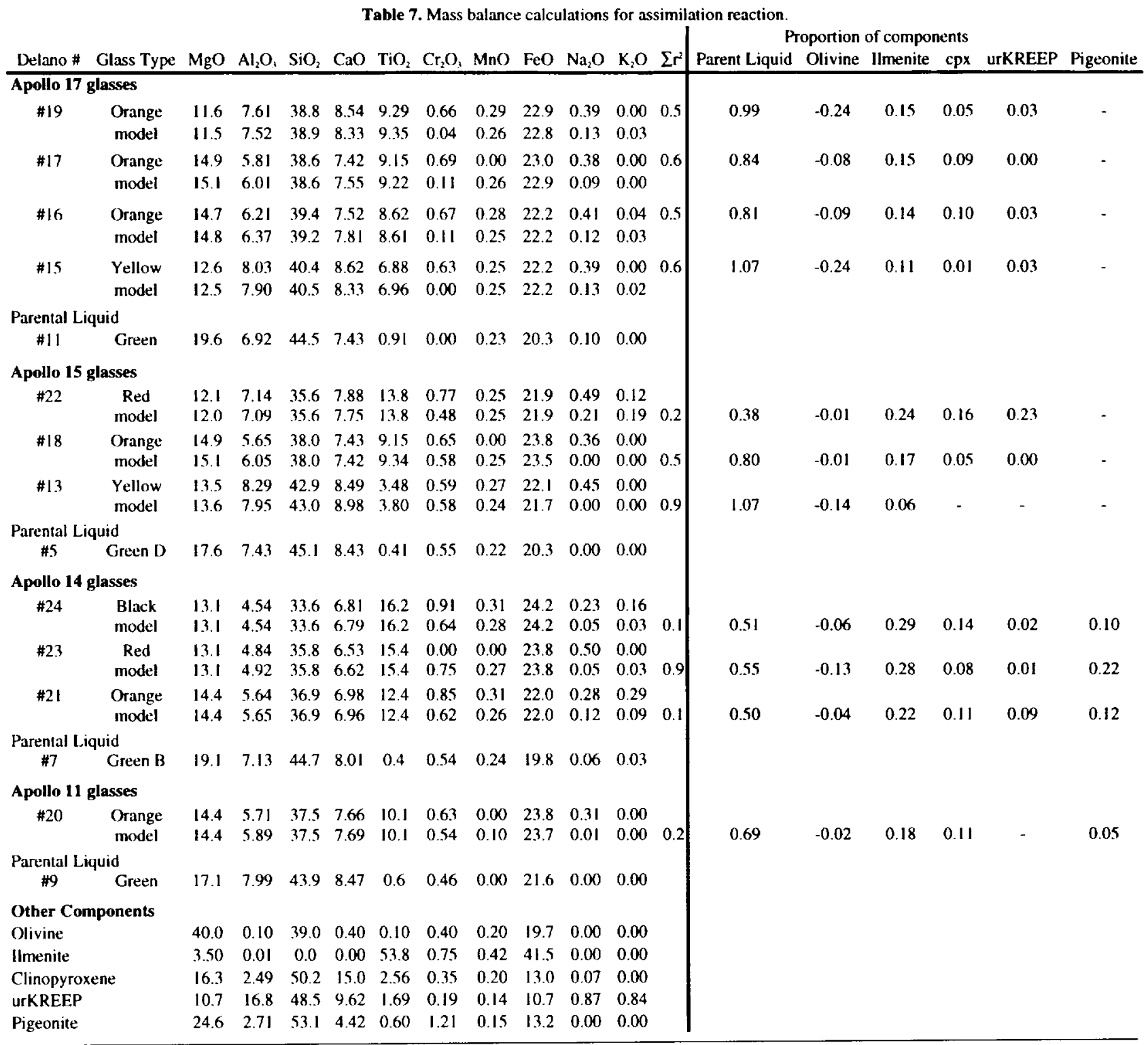

Model and Proportions of components were determined by multiple linear regression of parental green glass liquid and Other components against the high Ti glass compositions. Glass data is from Delano (1986). The olivine and pigeonite compositions are in equilibrium with the Apollo 15 green glass, from experiments of Green and Ringwood (1973). The ilmenite composition is from a highly evolved mare hasalt from Apollo 17, sample 70125 reported in Dymek et al. (1975). Clinopyroxene composition is an average from the crystallization experiment: of Grove and Beaty (1980) on the Apollo 11 high-K basalts. urKREEP composition is from Warren and Wasson (1979).

tions are not valid and that an assimilation model for the formation of high-Ti lunar magmas is plausible.

\subsubsection{Mass constraints on the assimilation model}

The assumption that magma ocean cumulates will be assimilated in bulk, i.e., the proportions in which they are present, is not valid since relative dissolution rates of ilmenite and cpx might exercise a control on the assimilation ratio. We estimated the proportions of assimilants through mass balance calculations involving multiple linear regression. A
low-Ti green glass parent and possible assimilants were used to model a variety of high-Ti glass compositions (Table 7). The range of possible assimilants was selected from the magma ocean crystallization model of Snyder et al. ( 1992). which is based on the MAGFOX and MAGPOX programs of John Longhi. According to the Snyder et al. ( 1992 ) model, the magma ocean reached ilmenite saturation after $95 \%$ crystallization while crystallizing an assemblage of ilmenite, cpx, pigeonite, and plagioclase. We assume that all plagioclase elutriated upward into the crust and have not included it in the regressions. The results of the regressions support this 
Table 8. Thermal energy budgets for assimilation.

\begin{tabular}{l|ccccr}
\hline \multicolumn{1}{c|}{ High Ti-glass formed } & $\Delta \mathrm{T}$, superheat ${ }^{\circ} \mathrm{C}$ & Heat avail $\left(\mathrm{cal} / \mathrm{g}_{\mathrm{q}}\right)$ & Heat required $\left(\mathrm{cal} / \mathrm{g}_{\mathrm{q}}\right)$ & $\Delta \mathrm{Heat}$ & $\%$ Diff \\
\hline AP 17 Orange (Delano \#19) & 110 & 57 & 22 & +35 & $+158 \%$ \\
AP 17 Orange (Delano \#17) & 110 & 43 & 29 & +14 & $+47 \%$ \\
AP 17 Orange (Delano \#16) & 110 & 44 & 32 & +12 & $+38 \%$ \\
AP 17 Yellow (Delano \#15) & 90 & 49 & 13 & +36 & $+283 \%$ \\
AP 15 Red (Delano \#22) & 130 & 42 & 136 & -94 & $-69 \%$ \\
AP 15 Orange (Delano \#18) & 110 & 34 & 26 & +8 & $+29 \%$ \\
AP 15 Yellow (Delano \#13) & 90 & 40 & 6 & +34 & $+580 \%$ \\
AP 14 Black (Delano \#24) & 160 & 61 & 104 & -44 & $-42 \%$ \\
AP 14 Red (Delano \#23) & 130 & 62 & 106 & -44 & $-41 \%$ \\
AP 14 Orange (Delano \#21) & 110 & 41 & 99 & -59 & $-59 \%$ \\
AP 11 Orange (Delano \#20) & 110 & 42 & 49 & -7 & $-14 \%$ \\
\hline
\end{tabular}

Calculated based on proportions from Table 7 . Constants used: $C_{\mathrm{p}}^{\text {hiquid }}=0.3-\mathrm{cal} /\left({ }^{\circ} \mathrm{C} * \mathrm{~g}\right) ; \Delta H_{\mathrm{f}}=100$-cal $/ \mathrm{gram}$ for olivine, ilmenite, and pigeonite; $\Delta H_{\mathrm{t}}=50$-cal/gram for urKREEP. Values for $\Delta H_{\mathrm{f}}$ are taken from Hon and Weill (1982), and Estimation of $\Delta T$ discussed in text.

decision, as no model compositions are deficient in $\mathrm{Al}_{2} \mathrm{O}_{3}$ or $\mathrm{CaO}$. We also assume that this layer contained urKREEP, the final dregs of magma ocean crystallization.

High-Ti glass compositions are recovered remarkably well for all major elements by the simple model. This is particularly important for FeO because one of the major arguments against an assimilation origin is that the $\mathrm{FeO}$ contents of high and low-Ti ultramafic glasses are very similar, and that formation of high-Ti magmas by ilmenite assimilation would also result in elevated $\mathrm{FeO}$ contents. As can be seen in Table 7, high-Ti contents can be produced in low-Ti parents with relatively modest increases in FeO if silicates are assimilated along with ilmenite. The results also show that mass balance always requires the assimilation of more ilmenite than $c p x$ and generally also requires the crystallization of olivine. $\mathrm{Pi}$ geonite and urKREEP assimilation is required by some, but not all models. The crystallization of olivine and assimilation of all other phases is consistent with expected phase equilibrium controls. The liquidi of the glass compositions are not

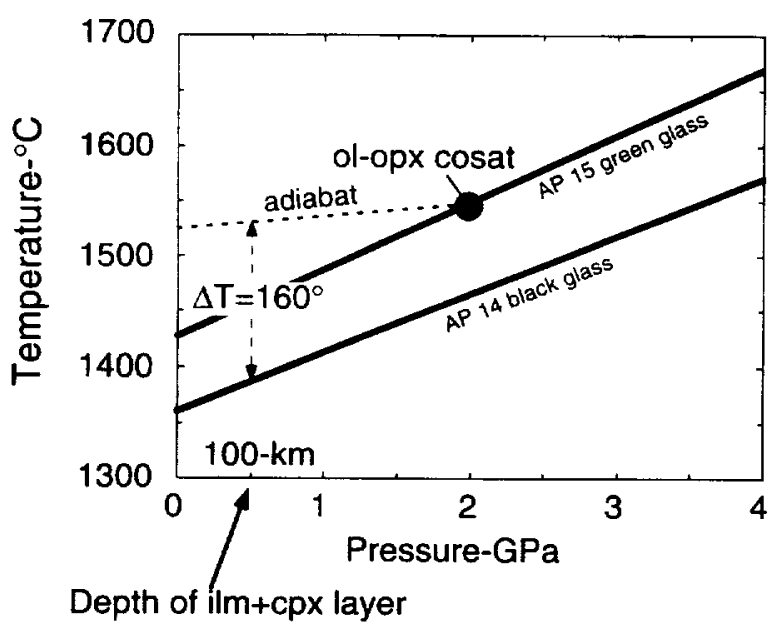

Fig. 8. Plot of the liquidi of Apollo 14 black glass (this study) and Apollo 15 green glass (T. L. Grove, unpubl. data). saturated with any of the assimilated phases at the $100-\mathrm{km}$ depth or 0.5-GPa pressure at which assimilation is inferred to take place. Low-Ti liquids are only saturated with olivine on their liquidi at these pressures, and high-Ti liquids are only saturated with ol or Cr-usp (Fig. 3; Kesson, 1975; Delano, 1980).

Assimilation of $20-30 \%$ late stage liquid is supported by the high trace element abundances of the Apollo 14 high-Ti ultramafic glasses (Shearer and Papike, 1992). The proportions dictated by mass balance are significantly lower than that and may indicate that major element mass balance models are not a sensitive indicator of the proportion of KREEP component, possibly because the major element composition of KREEP is difficult to constrain. The very low-alkali abundances of the model liquids relative to the high-Ti glass compositions may indicate that KREEP has much higher abundances of alkali elements than presently thought.

\subsubsection{Thermal energy constraints on the assimilation model}

The proportions of reactants (Table 7) were used to estimate the thermal energy budget of the assimilation reaction (Table 8 ). Heat for assimilation is provided from olivine crystallization and superheat due to adiabatic ascent of the primary liquid. Heats of fusion were assumed to be similar to those calculated by Hon and Weill (1982). The amount of superheat available can be calculated using the difference in liquidus temperatures between high and low-Ti glasses. The Apollo 15 green glass liquidus (T. L. Grove, unpubl. data) is approximately $100^{\circ}$ higher than the Apollo 14 black glass liquidus (Fig. 8). We assume that the green glass-type primary magma segregates from its source at the temperature and pressure at which it is multiply saturated with ol and opx, 2-GPa $(400-\mathrm{km})$ and $1550^{\circ} \mathrm{C}$. This melt ascends adiabatically to the ilmenite and cpx cumulate layer at $100-\mathrm{km}$ depth ( 0.5-GPa pressure, Fig. 8 ). At this point the liquid is $160^{\circ}$ hotter than the black glass liquidus (Fig. 8). Assuming the $C_{\mathrm{p}}^{\text {liquid }}=0.3-\mathrm{cal} /\left({ }^{\circ} \mathrm{C} * \mathrm{~g}\right)$; the difference in liquidi temperatures furnishes 48 -cal/(gram of green glass) from 
Table 9. Results of experimental studies of the dissolution rate of cpx.

\begin{tabular}{|c|c|c|c|c|c|c|}
\hline Press. (kb) & Temp. ${ }^{\circ} \mathrm{C}$ & $\mu \mathrm{m}$ diss. & Time (seconds) & Diss. rate $(\mathrm{cm} / \mathrm{s})$ & Ilm. Diss. Rate & Ratio ilm/cpx diss \\
\hline \multicolumn{7}{|c|}{ Zhang et al. 1989} \\
\hline 21.5 & 1375 & 56 & 1810 & 3.1E-06 & $9.5 \mathrm{E}-06$ & 3.1 \\
\hline 10.5 & 1305 & 40 & 4190 & 9.5E-07 & $2.4 \mathrm{E}-06$ & 2.5 \\
\hline \multirow{3}{*}{10.5} & 1305 & 26 & 890 & $2.9 \mathrm{E}-06$ & $2.4 \mathrm{E}-06$ & 0.8 \\
\hline & & & & & Average & 2.1 \\
\hline & \multicolumn{5}{|c|}{ Brearley and Scarfe 1986} & \\
\hline 5 & 1250 & & & 1.1E-06 & 8.1E-07 & 0.7 \\
\hline 5 & 1300 & & & $4.8 \mathrm{E}-06$ & $2.2 \mathrm{E}-06$ & 0.4 \\
\hline 12 & 1300 & & & $1.6 \mathrm{E}-07$ & 2.2E-06 & 13.6 \\
\hline 12 & 1350 & Tim & independent & $1.4 \mathrm{E}-06$ & $5.8 \mathrm{E}-06$ & 4.0 \\
\hline 12 & 1400 & & & $6.3 \mathrm{E}-06$ & $1.6 \mathrm{E}-05$ & 2.5 \\
\hline 30 & 1450 & & & $9.1 \mathrm{E}-07$ & 4.2E-05 & 46.4 \\
\hline \multirow[t]{2}{*}{30} & 1500 & & & $2.5 E-05$ & 1.1E-04 & 4.5 \\
\hline & & & & & Average & 7.3 \\
\hline
\end{tabular}

Data from Table 4, Brearley and Scarfe (1986) and Zhang et al. (1989).

the superheat for assimilation. The differences in liquidus temperature between the green glass and the red, orange, and yellow glasses were estimated by subtracting the difference between the temperature of their experimentally determined multiple saturation point and that of the black glass's (Table 8 ).

Superheat plus the heat of olivine crystallization provides more than enough heat for assimilation for most of the orange and yellow glass models with up to $10 \mathrm{wt} \% \mathrm{TiO}_{2}$. For the very high-Ti glasses, the red and black glasses, the superheat and olivine crystallization only provide about half of the heat required for assimilation. Some minor additional heat may be available during the formation of the red and black glasses due to the crystallization of Cr-usp. There also may be a larger amount of superheat available if low-Ti primary magmas are generated at greater depths than indicated by their ol + opx cosaturation point. Longhi (1992) suggests that the ol and opx cosaturation point of the green glass magmas is an artifact of aggregation of liquids produced by near-fractional decompression melting of the lunar mantle starting at depths $>1000-\mathrm{km}$ (5-GPa). For example. segregation of the low-Ti parent from the mean depths proposed by Longhi ( 1992 ) could provide sufficient heat for the assimilation reaction. Therefore, models for producing the Apollo 14 black, red, and orange ultramafic glasses must call upon low-Ti ultramafic magmas that segregated from greater depths, possessed higher liquidus temperatures than those used in the model presented in Table 8 and that have not yet been identified in the lunar samples. Moreover, the process could be more complex, as demonstrated by terrestrial magmatic systems where multiple injection and magma mixing occur and heat and mass transfer are decoupled (e.g., Hildreth and Moorbath, 1988; Baker et al., 1991 ). For these reasons we hesitate to develop more complex models than those outlined in Table 8.

\subsubsection{Kinetic constraints on the assimilation model}

All of the regression calculations show that more ilmenite must be assimilated than cpx to produce a high-Ti magma from a low-Ti parent (Table 7 ). The ratio of ilmenite to cpx assimilated varies from 1.4 to 8.7 , with an average value of $\sim 3$ (excluding the Apollo 15 yellow glass model which requires no pyroxene assimilation). Magma ocean crystallization models, however, show that much less ilmenite than cpx would be present in the magma ocean cumulate pile. For example, the crystallization model of Snyder et al. (1992) yields an ilmenite to cpx ratio of approximately 0.5 for the ilmenite-bearing cumulates. This discrepancy between the ratio dictated by mass balance and the likely proportion of these phases in the lunar interior offers a simple kinetic test of the assimilation model: if ilmenite dissolves significantly faster than cpx, assimilation is a feasible mechanism to produce high-Ti magmas, and if it does not, assimilation is not a feasible mechanism.

Although dissolution rate data for ilmenite did not exist before this study, the dissolution rate of cpx was determined by Brearley and Scarfe (1986) and Zhang et al. (1989). There are significant differences between these studies and our own in terms of liquid compositions studied and temperature, so only general inferences can be made. Brearley and Scarfe (1986) determined the dissolution rates of natural, mantle cpx in alkali olivine basalt by using spheres surrounded by melt. Their dissolution rates for cpx at 1.2-GPa are 2.5-14 times slower than our ilmenite dissolution rates at 1-GPa (Table 9. Fig. 4). Zhang et al. (1989) studied the dissolution of endmember diopside in andesitic liquid using the disk-sandwich technique employed here (Fig. 2). The Zhang et al. (1989) shortest duration experiment shows a diopside dissolution rate similar to the dissolution rate of ilmenite at this temperature (Table 9, Fig. 4), however, in the Zhang et al. (1989) experiments of similar duration to our own the dissolution rate of diopside is approximately three times slower than that of ilmenite.

The regression results require that ilmenite and $\mathrm{cpx}$ are assimilated in roughly a $3: 1$ ratio by weight or a $2: 1$ ratio by volume. The average ratio of our ilmenite and the Zhang et al. ( 1989) cpx dissolution rate data (Table 9) is 2:1, which matches the ilmenite/cpx volume dissolution ratio from mass balance. The ilmenite bearing layer of Snyder et al. 
(1992) contains ilmenite and cpx in a 1:2 ratio, which is an exact match for the ratio of the dissolution rates. This value, however, does not take into account the cpx crystallized prior to the onset of ilmenite crystallization.

A more complex model of the assimilation process is beyond the scope of present work. Kinetic aspects of assimilation in the lunar interior cannot be modeled directly because the relative proportions of assimilants are poorly constrained and more relevant dissolution rates for cpx must be determined. Based on the present results, we infer that the dissolution rate of ilmenite is significantly faster than that of cpx in lunar magmas, which supports assimilation as a viable mechanism to produce high-Ti ultramafic magmas.

\section{CONCLUSIONS}

We conclude that the high-Ti ultramafic glasses may be produced by assimilation of ilmenite $\pm \mathrm{cpx} \pm$ urKREEP \pm pig into low-Ti ultramafic primary magmas. This model is consistent with compositional, thermal, and kinetic aspects of the assimilation reaction. Assimilation must take place in the shallow lunar mantle in order for there to be sufficient superheat to drive assimilation.

Acknowledgments-This research was supported by NASA grant NAGW-3586. The authors thank J. Longhi, C. Shearer, and G. Snyder for reviews. A. Finnila, G. Gaetani, and P. Hess are thanked for helpful discussion. N. Shimizu (WHOI) and Carl Francis (Harvard Mineralogical Museum) provided ilmenite crystal used in the dissolution experiments.

Editorial handling: M. S. Ghiorso

\section{REFERENCES}

Agee C. B. and Circone S. (1995) Crystal-liquid density inversions in high-TiO2 lunar basalt. Lunar Planet. Sci. XXVI, 5-6.

Albee A. L. and Ray L. (1970) Correction factors for electron microprobe microanalysis of silicates, oxides, carbonates, phosphates and sulfates. Anal. Chem. 42, 1408-1418.

Anderson A. T. (1971) Exotic armalcolite and the origin of Apollo 11 ilmenite basalts. Geochim. Cosmochim. Acta 35, 969-973.

Baker M. B., Grove T. L., Kinzler R. J., Donnelly-Nolan J. M., and Wandless G. A. (1991) Origin of compositional zonation (highalumina basalt to basaltic andesite) in the Giant Crater lava field, Medicine Lake volcano, northern California. J. Geophys. Res. 96, 21819-21842.

Beaty D. W., Hill S. M. R., Albee A. L., Ma M.-S., and Schmitt R. A. (1979) The petrology and chemistry of basaltic fragments from the Apollo 11 soil, part I. Proc. IOth Lunar Planet. Sci. Conf., 41-75.

Bence A. B. and Albee A. L. (1968) Empirical corrections factors for the electron microanalysis of silicates and oxides. J. Geol. 76, $382-403$.

Boyd F. R. and England J. L. (1960) Apparatus for phase equilibrium studies at pressures up to $50 \mathrm{kbars}$ and temperatures up to $1750^{\circ} \mathrm{C} . J$. Geophys. Res. 65, 741-748.

Brearley M. and Scarfe C. M. (1986) Dissolution rates of upper mantle minerals in an alkali basalt melt at high pressure: an experimental study and implication for ultramafic xenolith survival. $J$. Petrol 27, $1157-1182$.

Chen H.-K. and Lindsley D. H. ( 1983 ) Apollo 14 very low-titanium glasses: Melting experiments in iron-platinum alloy capsules. $J$. Geophys. Res. 88, B335-B342.

Chen H.-K., Delano J. W., and Lindsley D. H. (1982) Chemistry and phase relations of VLT volcanic glasses from Apollo 14 and Apollo 17. J. Geophys. Res. 87, A171-A181.
Cooper A. R. (1962) Dissolution kinetics in glass making. In $A d-$ vances in Glass Technology: Technical Papers of the VI International Congress on Glass, Washington, DC, pp. 217-229. Plenum Press.

Delano J. W. (1980) Chemistry and liquidus relations of Apollo 15 red glass: implications for the deep lunar interior. Proc: 11th Lunar Planet. Sci. Conf., 251-288.

Delano J. W. ( 1986) Pristine lunar glasses: Criteria, data, and implication. J. Geophys. Res. 91, D201-D213.

Delano J.W. (1990) Buoyancy-driven melt segregation in the earth's moon, 1. Numerical results. Proc. 20th Lunar Planet. Sci. Conf., 3-12.

Dymek R. F., Albee A. L., and Chodos A. A. (1975) Comparative mineralogy and petrology of Apollo 17 mare basalts: Sample 70215, 71055, 74255, and 75055. Proc. 6th Lunar Sci. Conf. 4977.

Green D. H. and Ringwood A. E. (1973) Significance of a primitive lunar basaltic composition present in Apollo 15 soils and breccias. Earth Planet. Sci. Lett. 19, 1-8.

Green D. H., Ringwood A. E., Hibberson W. O., and Ware N. G. (1975) Experimental petrology of the Apollo 17 mare basalts. Proc. IIth Lunar Sci. Conf., 871-893.

Green D. H., Ringwood A. E., Ware N. G., Hibberson W. O., Major A., and Kiss E. (1971) Experimental petrology and petrogenesis of Apollo 12 basalts. Proc. 2nd Lunar Sci. Conf., 601-615.

Grove T. L. ( 1978) Cooling histories of the Luna 24 very low Ti (VLT) basalts: an experimental study. Proc. 9th Lunar Planet. Sci. Conf., 565-584.

Grove T. L. and Beaty D. W. (1980) Classification, experimental petrology and possible volcanic histories of the Apollo 11 high$\mathrm{K}$ basalts. Proc. 17th Lunar Planet. Sci. Conf., 149-177.

Grove T. L., Walker D., Longhi J., Stolper E. M., and Hays J. F. (1973) Petrology of rock 12002 and origin of picritic basalts at Oceanus Procellarum. Proc. 4th Lunar Sci. Conf., 995-1011.

Hays J. F. ( 1965 ) Lime-alumina-silica. Carnegie Inst. Wash. Yearbk. $65,234-236$.

Herbert F. (1980) Time dependent lunar density models. Proc. 1/th Lunar Planet. Sci. Conf., 2015-2030.

Hess P. C. (1991) Diapirism and the origin of high TiO2 mare glasses. Geophys. Res. Letr. 18, 2069-2072.

Hess P. C. (1993) The ilmenite liquidus and depths of segregation for the high-Ti picrite glasses. Lunar Planet. Sci. XXIV, 649650.

Hess P. C. and Parmentier E. M. (1995) A model for the thermal and chemical evolution of the moon's interior: Implications for the onset of mare volcanism. Earth Planet. Sci. Lett. 134, 501514.

Hildreth W. and Moorbath S. (1988) Crustal contributions to arc magmatism in the Andes of Central Chile. Contrib. Mineral. Petrol. 98, 455-489.

Hon R. and Weill D. F. (1982) Heat balance of basaltic intrusion vs granitic fusion in the lower crust. EOS, Trans $A G U$ 63, 470 (abstr.).

Hubbard N. J. and Minear J. W. (1975) A chemical and physical model for the genesis of lunar rocks: Part II. Mare basalts. Lunar Sci. VI, 405-407.

Kesson S. E. ( 1975) Mare basalts: melting experiments and petrogenetic interpretations. Proc. 6th Lunar Sci. Conf., 921-941.

Kesson S. E. and Lindsley D. H. (1976) The effects of $\mathrm{Al} 3+, \mathrm{Cr} 3+$ and Ti3 + on the stability of armalcolite. Proc. 6th Lunar Sci. Conf., 921-941.

Longhi J. (1977) Magma Oceanography 2: Chemical evolution and crustal formation. Proc. 8th Lunar Sci. Conf., 601-621.

Longhi J. ( 1992 ) Origin of picritic green glass magmas by polybaric fractional fusion. Proc. 22nd Lunar Planet. Sci. Conf., 343-353.

Longhi J., Walker D. Grove T. L. Stolper E. M., and Hays J. F. (1974) The petrology of the Apollo 17 mare basalts. Proc. 5th Lunar Sci. Conf., 447-469.

Putirka K., Johnson M., Kinzler R. J., Longhi J., and Walker D. (1996) Thermobarometry of mafic igneous rocks based on clinopyroxene-liquid equilibria, $0-30 \mathrm{~kb}$. Contrib. Mineral. Petrol. 123, $92-108$. 
Ridley W. 1., Reid A. M., Warner J. L., and Brown R. W. (1973) Apollo 15 green glasses. Phys. Earth Planet. Intl. 7, 133-136.

Ringwood A.E. and Kesson S. E. (1976) A dynamic model for mare basalt petrogenesis. Proc. 7th Lunar Sci. Conf., 1697-1722.

Shearer C. K. and Papike J. J. (1992) Relationship between Apollo 12 high-Ti, red picritic glass and high-Ti basaltic magmatism. Lunar Sci. XXIII, 1281-1282.

Smith J. V. et al. (1970) Petrologic history of the moon inferred from petrography, mineralogy, and petrogenesis of Apollo 11 rocks. Proc. 1st Lunar Sci. Conf., 897-825.

Snyder G. A., Taylor L. A., and Neal C. R. ( 1992) A chemical model for generating the sources of mare basalts: combined equilibrium and fractional crystallization of the lunar magmasphere. Geochim. Cosmochim. Acta 56, 3809-3823.

Spera F. J. (1992) Lunar magma transport phenomena. Geochim. Cosmochim. Acta 56, 2253-2265.
Taylor S. R. and Jakes P. (1974) The geochemical evolution of the moon. Proc. Sth Lunar Sci. Conf., 1287-1305.

Walker D., Longhi J., and Hays J. F. (1975a) Differentiation of a very thick magma body and implications for the source regions of the mare basalts. Proc. 6th Lunar Sci. Conf., 1103-1120.

Walker D., Longhi J., Stolper E. M., Grove T. L., and Hays J. F. (1975b) Origin of titaniferous lunar basalts. Geochim. Cosmochim. Acta 39, 1219-1235.

Warren P. H. (1985) The magma ocean concept and lunar evolution. Ann. Rev. Earth Planet. Sci. 13, 201-240.

Warren P. H. and Wasson J. T. (1979) The origin of KREEP. Rev. Geophys. Space Phys. 17, 73-88.

Wood J. A., Dickey J. S., Marvin U. B., and Powell B. N. ( 1970 ) Lunar anorthosites and a geophysical model of the moon. Proc. Ist Lunar Sci. Conf., $965-988$.

Zhang Y., Walker D., and Lesher C. E. (1989) Diffusive crystal dissolution. Contrib. Mineral. Petrol. 102, 492-513. 
